\title{
Bentuk Coping dan Pemahaman Masyarakat Dalam Menanggulangi Risiko Bencana
}

\author{
Wahyudi $^{1}$, Budijanto ${ }^{1}$, I Nyoman Ruja ${ }^{1}$ \\ ${ }^{1}$ Pendidikan Geografi-Universitas Negeri Malang
}

\begin{tabular}{l} 
INFO ARTIKEL \\
\hline Riwayat Artikel: \\
Diterima: 09-07-2019 \\
Disetujui: $17-03-2020$ \\
\hline
\end{tabular}

Kata kunci:

coping forms, community understanding; managing disaster risks; bentuk coping; pemahaman masyarakat; menanggulangi risiko bencana

\begin{abstract}
ABSTRAK
Abstract: This study is a qualitative and descriptive research employing phenomenology. The objective of this research is to identify individuals' understanding regarding preventing the risk of flood and coping form applied in Cotnga villagers' life. The data was collected through participatory observation and in-depth interview. The result of the study shows that the people's understanding in preventing the risk of annual flood forms a good understanding, and community-based anticipation in the form of simple and wise coping is carried out to enhance the capacity in reducing the risk of flood.

Abstrak: Jenis penelitian ini ialah deskriptif kualitatif dengan menggunakan pendekatan fenomenologi. Penelitian ini bertujuan untuk mengidentifikasi pemahaman individu tentang menangulangi risiko banjir dan bentuk coping yang diterapkan dalam kehidupan masyarakat Desa Cotnga. Teknik pengumpulan data dengan cara observasi partisipasi dan wawancara mendalam. Hasil penelitian menunjukkan bahwa pemahaman individu dalam menanggulangi risiko bencana banjir yang terjadi setiap tahunnya membentuk pemahaman yang baik, kemudian untuk meningkatkan kapasitas dalam mengurangi risiko bencana banjir dengan melakukan antisipasi berbasis masyarakat, yaitu bentuk coping sederhana yang bersifat arif.
\end{abstract}

\author{
Alamat Korespondensi: \\ Wahyudi \\ Pendidikan Geografi \\ Universitas Negeri Malang \\ Jalan Semarang 5 Malang \\ E-mail: Wahyudi.1607218@students.um.ac.id
}

Banjir merupakan peristiswa meluapnya air yang kemudian menggenangi permukaan tanah, banjir juga ancaman alam yang sering terjadi di Indonesia, intensitas hujan yang tinggi dengan durasi waktu yang lama merupakan satu faktornya, dimana curah hujan yang tinggi sehingga tidak dapat ditampung oleh sungai yang kemudian meluap ke area sekitarnya. Banjir juga disebabkan oleh pengendapan yang tinggi atau terkonsentrasi gelombang badai dan rusaknya sebuah tanggul, faktor yang harus dipertimbangkan. Misalnya faktor permasalahan drainase dalam perencanaan ini antara lain, debit banjir, penyempitan, dan pendangkalan saluran akibat desakan permukiman serta endapan sedimen, permasalahan sampah (Khatab \& Indrawan, 2013). Banjir juga menjadi ancaman yang terjadi disetiap musim penghujan (Triuri \& Marwasta, 2013). Juga disebabkan oleh Pemanasan global yang meningkatkan besarnya dan frekuensi peristiwa curah hujan ekstrem yang dapat menyebabkan banjir sungai lebih intens dan sering terjadi (Dankers \& Feyen, 2008). Seperti halnya yang dirasakan oleh masyarakat Desa Cotnga bila musim hujan datang maka fenome banjir akan segera mereka rasakan.

Penduduk Cotnga manyoritas bekerja sebagai petani, Desa Cotnga berada di Kecamatan Peusangan Kabupaten Bireuen. Bedasarkan letak geografisnya Desa Cotnga bertetangga dengan desa lain di antaranya ialah sebelah utara berbatasan dengan Desa Matamamplam, selatan berbatasan dengan Desa Cot Iju, timur berbatasan dengan Desa Cot Panjoe dan Sebelah barat berbatasan dengan Desa Puloe Naleung. Desa Cotnga ialah desa yang setiap tahun mengalami bencana banjir, "Banjir disebabkan karena jebolnya tanggul irigasi yang melintasi Desa Cot Keuranji ke Desa Cotnga sehingga air tersebut mengalir ke area persawahan dan pemukiman warga, dan tidak hanya jebol, tetapi akan meluap di saat musim hujan datang dengan intensitas tinggi". (wawancara 25 maret, 2017). Maka dari kejadian setiap tahunnya diperlukan tindakan yang paling esensial dan prinsipprinsip dalam strategi pengurangan banjir secara alami dengan diilustrasikan oleh slogan-slogan "jaga air tetap mengalir" dan "kembalikan air ke bantaran sungai" (Kundzewicz \& Menzel, 2005).

Irigasi Cotnga Desa sumber airnya berasal dari daerah aliran sungai (DAS) peusangan dengan sumber hulunya di Lut tawar Takengon, melintasi lima kabupaten kota, yaitu Kabupaten Aceh Tengah, Bener Meriah, Lhokseumawe, Aceh Utara, dan Bireuen. Kabupaten Bireuen tepatnya di Desa Cotnga Kecamatan Peusangan merupakan salah satu sub daerah aliran sungai peusangan, berhilir ke laut jangka, Desa Cotnga merupakan satu desa yang menampung air dari irigasi yang berasal dari Cot Panjoe - Cotnga, Cot Keuranji - Cotnga dan Cot Iju - Cotnga, ketiga irigasi tersebut berarah ke Desa Cotnga dan kemudian baru mengalir ke hilir, maka disaat musim hujan tiba, dengan intensitas tinggi air dari ketiga aliran irigasi tersebut tidak dapat 
ditampung oleh irigasi Desa Cotnga sehingga mengalami kerusakan atau jebol setiap tahunnya sehingga meluap ke area persawahan dan pemukiman. Masyarakat Cotnga menyebutkan peristiwa ini ialah banjir kiriman.

Masyarakat Cotnga mempunyai cara tersendiri dalam menanggulangi risiko bencana yang dihadapinya, mulai dari menyiapkan rumah panggung untuk menaruh barang agar terhindar dari air banjir, kemudian menyiapkan bibit padi cadangan untuk antisipasi di saat padi dalam sawah sudah mati. Kerugian dirasakan tidaklah signifikan, tetapi kerugian waktu yang berdampak pada aktivitas sehari-hari dengan genangan air mencapai $50 \mathrm{~cm}$ yang menyisakan sampah-sampah, lama genangan tiga sampai lima hari lamanya. Banjir yang terus menerus terjadi setiap tahunnya, maka masyarakat Desa Cotnga mempunyai cara tersendiri dalam menanggulangi risikonya. Bentuk antisipasi tersebut dikenal dengan nama coping, secara teoritis coping ialah upaya individu baik secara kognitif, afektif dan perilaku guna mengelola tuntutan eksternal dan internal secara spesifik (Folkman et al, 1986). Sebagaimana di negara lain, seperti Brazil, masyarakat berkerja sama dalam memulai untuk mengembangkan strategi mitigasi yang efektif untuk berurusan dengan alam dan manusia (Hewitt, 2005).

Bedasarkan teori, Coping mempunyai dua aspek dan delapan bentuk, di antaranya aspek Problem Focused Coping dan Emotion Focused Coping, kemudian delapan bentuknya ialah Konfrontatif, pencarian dukungan sosial, pemecahan masalah yang terencana, kontrol diri, pengalihan, penilaian positif, penerimaan tanggung jawab dan menghindar (Folkman et al., 1986). Beberapa hal yang terlaksana pada masyarakat Desa Cotnga dalam hal menanggulangi bencana banjir, walaupun ada sedikit perbedaan sedikit dari cara pandang dalam memaknai sebuah peristiwa.

Penelitian ini bertujuan untuk mengidentifikasi pemahaman individu dalam menangulangi risiko bencana banjir dan antisipasi dalam bentuk coping yang diterapkan oleh masyarakat Desa Cotnga, antisipasi ditafsirkan sebagai keputusan dan tindakan yang dilakukan untuk mengurangi risiko yang tersisa banjir (Schanze et al., 2006). Penulis menetapkan informan kunci ialah individu asli Desa Cotnga yang mempunyai sawah dan lading serta yang pernah mengalami kerugian akibat banjir yang pernah melanda informan tersebut, wawancara informan pada tanggal 17 maret 2017, banjir di Desa Cotnga disebabkan oleh limpasan air sungai peusangan yang mengalir ke Cotnga melalui tiga irigasi yaitu Cot Panjoe, Cot Keuranji, dan Cot Iju. Lebih lanjut disampaikan oleh informan berikutnya yang merupakan perangkat desa "banjir terjadi juga dikarenakan pendangkalan dan sempitnya irigasi tidak sesuai dengan kapasitas air yang masuk sehingga mengalami kebocoran dan patah sehingga berdampak ke area pemukiman warga Desa Cotnga" (wawancara tanggal 20 maret, 2017).

\section{METODE}

Penelitian ini mengadopsi metode kualitatif dengan pendekatan fenomenologi. Fenomenologi ini dipilih karena mempunyai kekhususan yang diyakini sesuai dengan fokus penelitian, perspektif fenomenologi yang digunakan yaitu fenomenologi dari Alfred Schutz dikarenakan menjelaskan suatu pemaknaan atau pemahaman yang tidak lepas dari dua motif ialah motif sebab (because motive) dan motif tujuan (in order to motive). Perspektif ini dilaksanakan dengan meneliti fenomena yang akan dikembangkan dengan penggalian data melalui informasi pada pendekatan berupa tindakan para pelaku fenomena. Tujuannya untuk memahami makna kejadian, gejala yang ada, dan atau interaksi individu dalam kondisi serta situasi tertentu dalam kehidupan sehari-hari di masyarakat tertentu (Fatchan, 2013). Untuk mencapai pemulihan yang cepat dan efektif diperlukan manajemen pengetahuan guna meningkatkan proses manajemen bencana atau cara menanggulangi risiko yang dirasakan dalam koordinasi informasi dan sebagainya dalam konteks manajemen bencana (Seneviratne et al., 2010).

Perspektif ini menghendaki beberapa interpretasi sampai akhirnya masuk ke dalam dunia makna (pemahaman) dan dunia konsep bedasarkan konsep subjek penelitian. Informan yang ditentukan dalam penelitian ini tidaklah semua elemen individu masyarakat Desa Cotnga, melainkan beberapa informan dengan ketentuan mencapai kategori yang telah ditetapkan sesuai dengan pokok permasalahan tujuan penelitian. Identifikasi yang disyaratkan, meliputi (1) penduduk asli Desa Cotnga Kecamatan Peusangan Kabupaten Bireuen; (2) individu yang berumur 25 tahun ke atas; (3) pernah menjadi korban banjir.

Data diambil melalui observasi partisipasi serta wawancara mendalam, observasi partisipasi yang dilakukan tidaklah penuh mengingatkan keterbatasan waktu bagi peneliti. Data analisis dilakukan dengan cara analisis kasus per kasus secara simultan. (Sugiyono, 2016), mengemukakan bahwa adanya kegiatan yang dilakukan secara interaktif dan terus menerus sampai tuntas dalam analisis kualitatif sehingga datanya jenuh, analisisnya berupa data reduction, dan display serta conclution, drawing/ verification. Tahap berikutnya tahap penyelesaian dengan melakukan beberapa langkah, meliputi (1) melakukan observasi partisipasi; (2) melakukan pengamatan terhadap apa yang dibicarakan subjek; (3) melakukan analisis deskripsi dan pengecekan keabsahan dari data dengan melakukan wawancara mendalam melalui dialog dengan subjek penelitian; (4) melakukan analisis subtansial dan pengecekan keabsahan; (5) menemukan pemahaman subjek yang diteliti (Fatchan, 2013).

\section{HASIL}

\section{Bentuk Coping dan Pemahaman Informan I}

Informan I memastikan banjir di desa Cotnga terjadi setiap akhir dan awal tahun, yaitu bulan November dan Januari tahun berikutnya. Dari peristiswa tersebut ancaman yang paling utama disebabkan adalah luapan air irigasi yang bersumber dari DAS Peusangan, dan diperparah lagi jika terjadi hujan lebat dengan durasi waktu lebih dari satu jam, maka dapat menenggelamkan padi dan sampah ke dalam sawah. Kerentanan yang paling merugikan masyarakat ialah terjadinya gagal panen, maka dari itu munculah sebuah tindakan untuk menanggulangi risiko dari peristiwa banjir yaitu perilaku coping dengan berbagai bentuk 
antisipasinya yang terbagi menjadi dua aspek, yaitu (1) aspek Problem-Focused Coping dengan bentuk konfrontatif yaitu menaruh hewan ternak di Bale atau rumah panggung yang telah ditinggikan, kemudian mencari bantuan sosial untuk mengangkat barang bersama anak-anaknya, dan untuk pemecahan masalah yang terencana dengan bentuk serta tahapan-tahapan yang telah dipikirkan berupa penyelamatan mulai dari barang-barang elektronik, hewan ternak dan persiapan dapur darurat; (2) aspek Emotion Focused Coping pada Informan I terlihat dari bentuk kontrol diri dengan baik, berusaha tenang walaupun sedang mengalami bencana banjir, penilaian positif berupa memaknai peristiwa banjir ini merupakan teguran dari Allah, kemudian menghilangkan rasa jenuh dengan cara mengobrol sesama tetangga dengan harapan ada solusi yang terbaik guna meminimalisirkan dampak yang akan ditinggalkan oleh banjir.

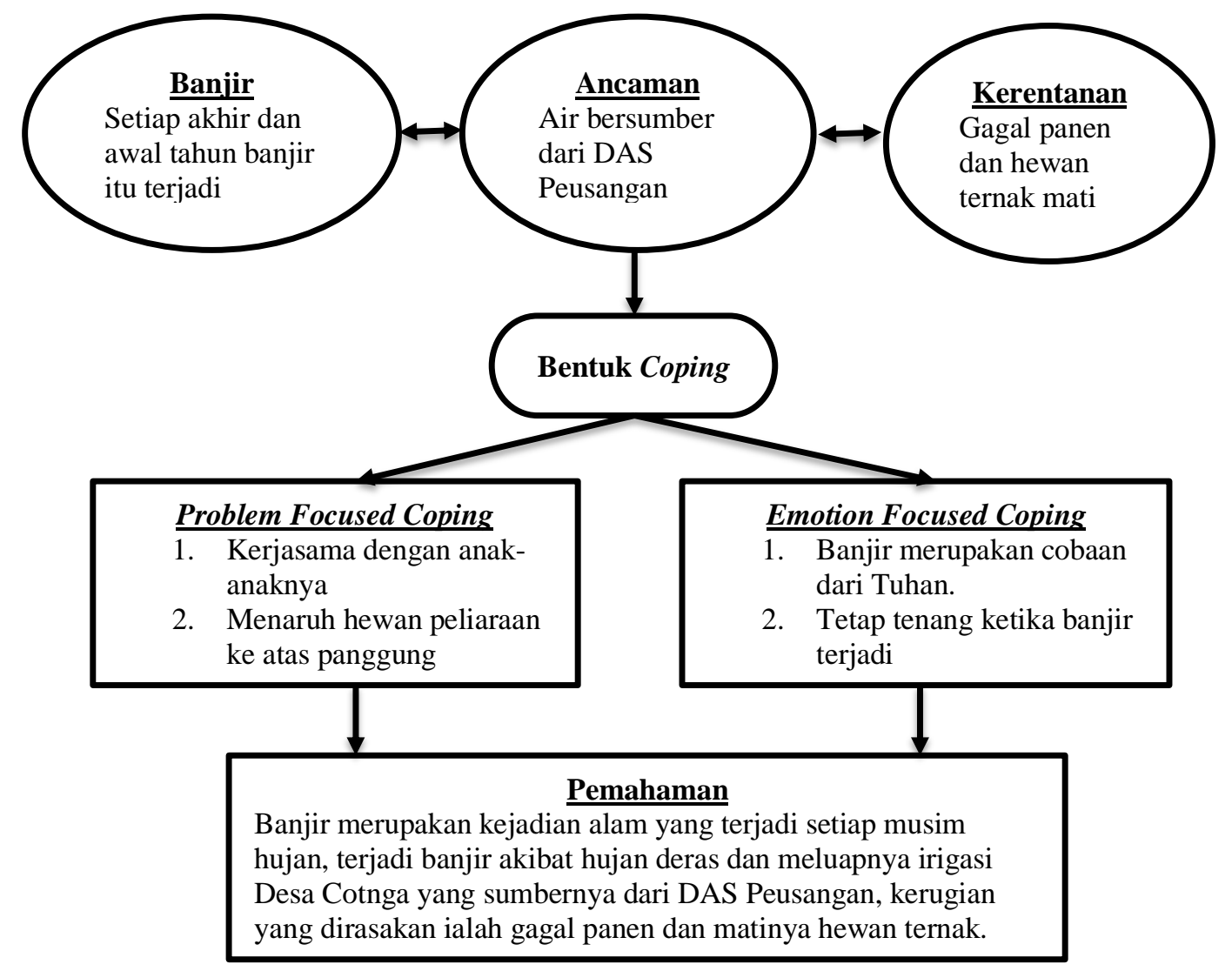

Gambar 1. Skema Bentuk Coping dan Pemahaman Informan I

Bentuk Coping dan Pemahaman Informan II

Informan II membenarkan bahwa banjir yang dialami oleh masyarakat Cotnga terjadi setiap tahun, informan menjelaskan bahwa irigasi sudah diperbaiki dan diperdalam akan tetapi banjir tetap ada dengan kata lain sudah jadi langganan setiap tahun. Ancaman yang signifikan menurut informan II ialah curah hujan yang tinggi dari bukit atau hulu kemudian mengalir ke Desa Cotnga dengan deras. Untuk kerentanan apabila banjir terjadi disaat padi baru ditanam, maka harus ditanam ulang dengan bibit yang baru kemudian sawah harus dibersihkan dari sisa-sisa sampah dengan biaya baru lagi, informan II menjelaskan kerugian yang dialaminya sekitar dua juta untuk sekali penanaman ulang, maka bentuk coping yang dilakukannya ialah sebagai berikut.

Pertama, aspek Problem Focused Coping muncul dalam bentuk konfrontatif dengan cara mencari informasi dari orang lain untuk antisipasi agar lebih siaga, sedangkan untuk dirumah sudah menyiapkan Bale atau rumah panggung serta meja yang telah ditinggikan untuk sekedar menahan beban agar tidak terjangkau air, dalam proses Coping informan memiliki tahapan dalam penyelamatan barang-barangnya mulai dari kendaraan, alat elektronik dan pakaian. Kedua, aspek Emotion Focused Coping pada informan II adanya rasa khawatir jika banjir semakin tinggi karena besar kemungkinan tanggul irigasi akan jebol kembali dan akan berdampak parah ke area sawah warga, namun informan masih dapat mengontrol diri dan berusaha menghadapi peristiwa banjir dengan cara tidak gegabah, informan sangat yakin bahwa banjir merupakan cobaan yang akan ada hikmah setelahnya, baiknya itu keuntungan saat panen dan bersihnya lingkungan dari hama tikus. 


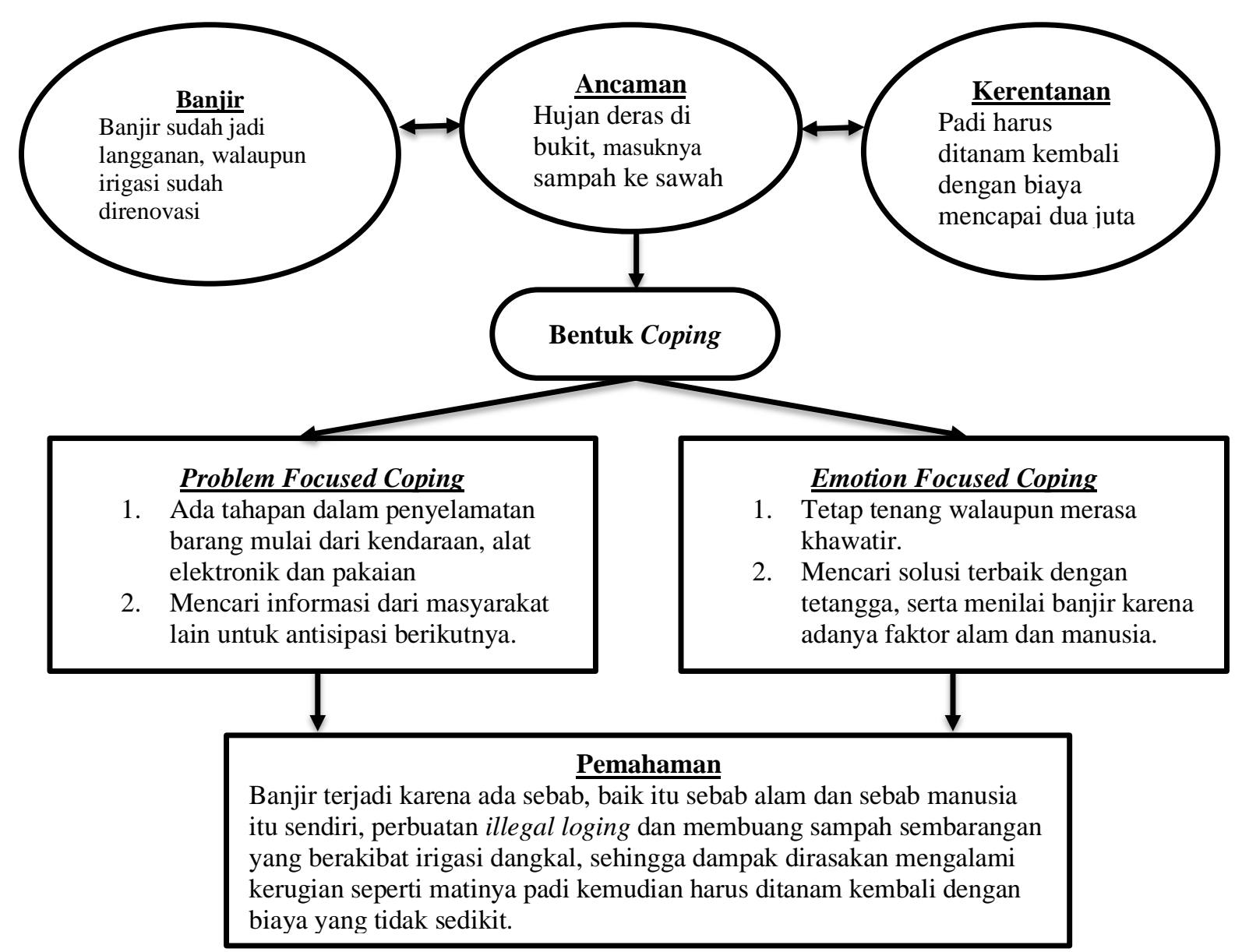

\section{Gambar 2. Skema Bentuk Coping dan Pemahaman Informan II}

\section{Bentuk Coping dan Pemahaman Informan III}

Informan III mengetahui Desa Cotnga mengalami peristiswa banjir dari tahun ke tahun, semenjak informan lahir sampai sekarang banjir selalu menghampiri Desa Cotnga, diantara beberapa banjir yang telah terjadi informan menjelaskan tahun 2002 merupakan banjir yang sangat parah dampaknya dibandingkan sepuluh tahun terakhir, yaitu dengan air mencapai satu meter atau sepinggang orang dewasa. Kerentanan dominan yaitu matinya ternak, dan gagal panen serta rusaknya infratruktur umum berupa jalan dan lorong-lorong di pemukiman, dari akumulasi kejadian tersebut munculah bentuk coping dari informan III berupa:

1. Aspek Problem Focused Coping bentuk konfrontatif berupa menambak perkarangan rumah dan membangun Bale atau rumah panggung guna menaruh barang-barang yang akan diselamatkan, dukungan sosial juga dilakukan sesame keluarga seperti anak istri dalam mengangkat kasur dan televisi. Tahapan penyelamatan dari informan III yaitu mulai dari hewan peliarahan seperti kambing dana yam dan juga kendaraan, kasur, televisi, dan baju.

2. Aspek Emotion Focused Coping dari informan III sangat bagus walau masih cemas dengan air yang semakin deras ketika banjir mulai terjadi ditengah malam, tetapi informan tetap berusaha mengontrol diri dengan baik, aspek pengalihan sangat jelas dilakukannya karena informan yakin peristiwa ini terjadi disebabkan oleh faktor manusia itu sendiri bukan karena takdir, penilaian positif juga dimunculkan dengan saling membantu dan aspek menghindar sangat kuat yaitu berusaha mengobrol dengan baik sesame tetangga untuk saling membantu. 


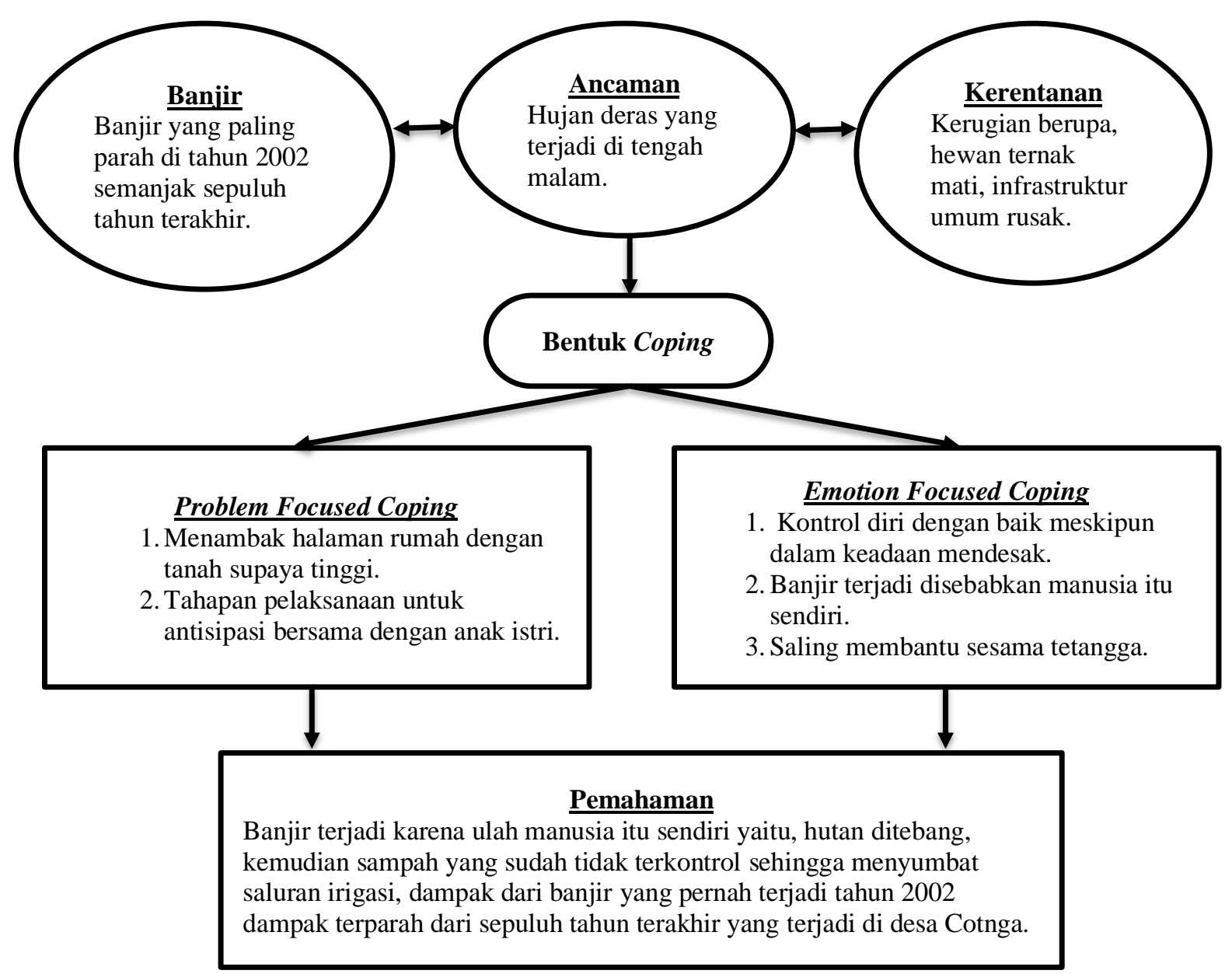

Gambar 3. Skema Bentuk Coping dan Pemahaman Informan III

\section{PEMBAHASAN}

Pemahaman serta bentuk perilaku yang sudah diterapkan oleh masyarakat Desa Cotnga merupakan kajian psikososial yang masih jarang atau relatif masih baru dalam ilmu Geografi. Pemahaman masyarakat sangatlah natural yang dilihat dari alam itu sendiri, banjir dapat diperkirakan dan diprediksi meskipun tingkat risikonya tidak pasti (Shultz et al., 2013). Hal ini menyebabkan adanya kekhawatiran pandangan yang salah terhadap beberapa penggunaan tata bahasa dan istilah dalam masalah kebencanaan dan istilah dalam bahasa Aceh itu sendiri yang berlaku di masyarakat Desa Cotnga, seperti Bale, Rumoeh Panggong dan lain sebagainya. Paparan dari ketiga informan penelitian ini sudah sangat jelas tentang apa yang telah dilakukan dan difenomenakan dalam menanggulangi risiko bencana banjir yang terjadi di Desa Cotnga, peristiswa ini sangat membekas, baik dalam psikologis dan sosial. Masyarakat Cotnga ingin tahu selalu dan membutuhkan informasi mengenai bencana yang terjadi setiap tahun dengan mencari solusi yang terbaik agar tidak berdampak di lain tempat dan terulang setiap tahunnya, misalnya mengenai penyebab, kerugian dan penanggulangannya, pemahaman masyarakat berbeda-beda dalam menginterpretasikan sebuah peristiwa tersebut.

Pemahaman individu berbeda-beda, tetapi itu tidak menjadi alasan berbeda dalam atau cara menanggulangi risiko bencana banjir di Desa Cotnga. Implementasi langkah-langkah perlindungan banjir secara tradisional sangat penting, namun peningkatan peran harus dimainkan khususnya oleh pencegahan banjir itu sendiri (Vojtek \& Vojteková, 2016). Maka kemudian untuk meminimalisirkan dampak yang terjadi dalam peristiwa banjir, tindakan masyarakat Cotnga tidak lepas dari faktor motif sesuai dengan pendekatan yang dilakukan Schutz, (1972) yaitu motif "sebab" dikarenakan adanya bencana yang setiap tahun terjadi sehingga lahirnya sebuah tindakan, dan motif "supaya" atau "tujuan" agar dapat meminimalisir dampak dari bencana banjir sehingga terbentuklah perilaku coping yang berbasis masyarakat.

Bentuk perilaku yang difenomenakan oleh tiga informan dalam penelitian ini menunjukkan bahwa cukup mengerti apa yang dirasakan dan kemudian menghadapi bencana dengan cara yang sudah diterapkan dari tahun ke tahun, semua ini tidaklah lepas dari faktor motif sebab dan motif tujuan yang akan dicapai, dari delapan bentuk coping, ada beberapa bentuk yang sama dalam menerapkan ketika bencana banjir dirasakan oleh ketiga informan tersebut, di antaranya ialah bentuk konfrontatif, ketiga informan serupa melakukan bentuk coping berupa meninggikan Bale atau rumah panggung guna menempatkan barang-barang 
untuk diselamatkan dari banjir. Hanya perbedaan istilah dimana ketiga informan tersebut melakukan hal yang sama dengan orang yang berbeda dan jumlah keluarga dalam melakukan bentuk coping.

Bentuk pencarian dukungan sosial juga muncul dari ketiganya, baik itu dengan anak istrinya dan juga sesame tetangga informan, kemudian bentuk pemecahan masalah yang terencana, semua informan menerapkan barang apa yang pertama harus diselamatkan hanya saja bentuk dan barang yang berbeda dari ketiga informan namun dari ketiganya melakukan tahapan dalam menyelamatkan barang-barangnya. Kemudian dari bentuk pengalihan informan I dan III menyatakan hal serupa bahwa banjir terjadi karena ada faktor pemicunya, yaitu manusia itu sendiri bukan karena kehendak dari Tuhan semata.

Bentuk penilaian positif juga sama-sama diperlihatkan hanya saja informan I yang lebih dominan dengan mengatakan banjir terjadi karena kehendak atau kuasa dari Tuhan, tetapi informan I tidak mau berburuk sangka terhadap orang lain karena jika musibah sudah menjadi kehendak Tuhan, maka manusia hanya dapat menerima dan tidak dapat mengubah atas apa yang sudah ditentukan dalam kodratnya, kemudian bentuk penerimaan tanggung jawab juga diperlihatkan semua informan, sederhananya setiap individu mempunyai peran dalam keluarganya dan di masyarakat sekitar seperti tetangga informan.

Kemudian bentuk lari atau pola menghindar juga muncul dari ketiga informan penelitian, mulai dari mencari dukungan dengan sesama tetangga mulai dengan mengobrol untuk mencari solusi bersama untuk menangulangi risiko bencana yang akan berdampak kepada semua individu Desa Cotnga. Dari intensitas yang terindentifikasi dari ketiganya, jelas bahwa masyarakat Desa Cotnga hampir semua memunculkan bentuk coping, hanya saja berbeda dalam bentuk materi yang diselamatkan dan jumlah keluarga ketika menanggulangi banjir. Maka strategi penanggulangan banjir ini sangat membantu masyarakat di desa lain sebagaimana pembentukan langkah-langkah ini telah diterapkan masyarakat China dan memainkan peran penting dalam mitigasi bencana banjir yang terjadi di Danau Dongting (Zeng et al,. 2001).

\section{SIMPULAN}

Penulis menyimpulkan bahwa bentuk coping dan pemahaman masyarakat dalam menanggulangi banjir di Desa Cotnga Kecamatan Peusangan Kabupaten Bireuen sebagai berikut.

Pertama, bentuk coping dan pemahaman masyarakat Cotnga sangatlah baik dalam memahami bencana banjir, dimana peristiwa ini telah terjadi dan dirasakan setiap tahunnya pada musim penghujan, masyarakat Desa Cotnga bisa memperkirakan banjir akan mendatangi mereka ketika hujan sudah terjadi di bukit dengan deras dan durasi waktu lebih dari satu jam, kemudian diperkuat lagi perkiraan ketika air dalam irigasi sudah keruh, maka masyarakat Cotnga mulai bersiaga untuk menaruh barangbarang yang kemudian diselamatkan ke tempat yang telah dipersiapkan seperti Bale atau rumah panggung.

Kedua, individu Desa Cotnga sudah melakukan antisipasi berbasis masyarakat untuk mencegah dampak dari peristiwa banjir, walaupun tidak bisa memperkirakan seberapa besar risiko yang akan terjadi namun masyarakat cukup memahami dengan melihat gejala alam bedasarkan filing dan juga pengalaman sebelumnya sehingga dengan segera melakukan tindakan coping.

Ketiga, Problem Focused Coping paling dominan ialah bentuk coping konfrontatif dan pemecahan masalah yang terencana, yaitu berupa bentuk perilaku menaikkan barang-barang ke tempat tinggi yang sudah disediakan, kemudian ada tahapantahapan dalam menyelamatkan barang serta mencari dukungan sosial dengan tetangga.

Keempat, Emotion Focused Coping terlihat pada banyaknya berorientasi pada bentuk kontrol diri yang baik dan lari untuk menghindar, sedangkan pengalihan tidak semua dominan kemudian penilaian positif penerimaan tanggung jawab berbeda setiap individu dalam memaknai fenomena yang sedang terjadi ketika individu mengalami peristiswa banjir.

Kelima, peneliti mengharapkan tulisan ini dapat membantu peneliti selanjutnya, dan menjadi rujukan yang bermanfaat bagi semua elemen masyarakat dan mahasiswa dalam melakukan penelitian di masyarakat mengenai banjir dan bentuk mitigasi diberbagai tempat.

Keenam, untuk Pemerintah Kabupaten Bireuen dapat meningkatkan kepedulian terhadap masyarakat khususnya masyarakat Desa Cotnga untuk memenuhi kebutuhan ketika banjir melanda desa mereka, kemudian memfasilitasi apa yang dapat meringankan beban masyarkat Desa Cotnga ketika menanggulangi banjir.

\section{DAFTAR RUJUKAN}

Dankers, R., \& Feyen, L. (2008). Climate Change Impact on Flood Hazard in Europe: An Assessment Based on HighResolution Climate Simulations. Journal of Geophysical Research, 113(D19), D19105. https://doi.org/10.1029/2007JD009719

Fatchan, A. (2013). Metode Penelitian Kualitatif, 10 Langkah Penelitian Kualitatif. Pendekatan Konstruksi dan Fenomenologi. Malang: Universitas Negeri Malang.

Folkman, S., Lazarus, R. S., Gruen, R. J., \& DeLongis, A. (1986). Appraisal, Coping, Health Status, and Psychological Symptoms. Journal of Personality and Social Psychology, 50(3), 571-579. https://doi.org/10.1037/00223514.50.3.571

Hewitt, W. E. (Ted). (2005). Developing Effective Disaster Mitigation Strategies in São Paulo: Process and Challenges. Canadian Journal of Latin American and Caribbean Studies, 30(60), 41-61. https://doi.org/10.1080/08263663.2005.10816878 
Khatab., \& Indrawan, I. (2013). Evaluasi Waduk Pusong sebagai Upaya Pengendalian Banjir di Kota Lhokseumawe Kabupaten Aceh Utara. Jurnal Teknik Sipil USU, 2(3), 1-10.

Kundzewicz, Z. W., \& Menzel, L. (2005). Natural flood reduction strategies - a challenge. International Journal of River Basin Management, 3(2), 125-131. https://doi.org/10.1080/15715124.2005.9635252

Nindito, S. (2013). Fenomenologi Alfred Schutz: Studi tentang Konstruksi Makna dan Realitas dalam Ilmu Sosial. Jurnal Ilmu Komunikasi, 2(1). https://doi.org/10.24002/jik.v2i1.254

Schanze, J., Zeman, E., \& Marsalek, J. (Eds.). (2006). Flood risk management: Hazards, vulnerability and mitigation measures. Dordrecht: Springer.

Seneviratne, K., Baldry, D., \& Pathirage, C. (2010). Disaster Knowledge Factors In Managing Disasters Successfully. International Journal of Strategic Property Management, 14(4), 376-390. https://doi.org/10.3846/ijspm.2010.28

Shultz, J. M., McLean, A., Herberman Mash, H. B., Rosen, A., Kelly, F., Solo-Gabriele, H. M., ... Neria, Y. (2013). Mitigating flood exposure: Reducing Disaster Risk and Trauma Signature. Disaster Health, 1(1), 30-44. https://doi.org/10.4161/dish.23076

Triuri, Z., \& Marwasta, D. (2013). Strategi Adaptasi Masyarakat Dalam Menghadapi Banjir di Kecamatan Tebet, Kota Jakarta Selatan (Studi Kasus Daerah Bantaran Sungai Ciliwung). 8.

Vojtek, M., \& Vojteková, J. (2016). Flood Hazard and Flood Risk Assessment at the Local Spatial Scale: A Case Study. Geomatics, Natural Hazards and Risk, 7(6), 1973-1992. https://doi.org/10.1080/19475705.2016.1166874

Zeng, G. M., Xie, Z., Zhang, S. F., \& Luo, X. (2001). Flood Disaster and Non-engineering Mitigation Measures in Dongting Lake in China. Water International, 26(2), 185-190. https://doi.org/10.1080/02508060108686903 